\title{
Long-term efficacy of AMS 800 artificial urinary sphincter in male patients with urodynamic stress incontinence due to spinal cord lesion
}

\author{
P Patki*,1, R Hamid ${ }^{1}$, PJR Shah ${ }^{1,2}$ and M Craggs ${ }^{1,2}$ \\ ${ }^{1}$ Spinal Injuries Unit, Royal National Orthopaedic Hospital, Stanmore, Middlesex, UK; ${ }^{2}$ Institute of Urology \\ and Nephrology, London, $U K$
}

Study design: Retrospective analysis.

Objectives: To evaluate long-term efficacy and complications of AMS 800 (American Medical Systems ${ }^{\mathbb{R}}$ ) artificial urinary sphincter (AUS) in treatment of urodynamic stress incontinence (USI) in male patients with spinal cord lesion (SCL).

Setting: London Spinal Injuries Unit, Stanmore, UK and Institute of Urology and Nephrology, London, UK.

Patients and methods: A retrospective analysis identified nine males with SCL (five thoracic, three lumbar, one cervical) with USI, who underwent AMS 800 AUS implantation by a single surgeon at a specialist spinal injuries unit. The mean age was 38.2 years (range 27-47 years), with the mean time since injury of 13.8 years (range 6-26 years). In all, seven were complete and two were incomplete SCL (traumatic spinal injury eight, tranverse myelitis one). All implants were inserted with the urethral cuff around the bulbar urethra with a $61-70 \mathrm{~cm}$ water pressure reservoir in the retropubic space. Implant activation was carried out at 6 weeks postoperatively. All patients were regularly followed up in outpatient clinics at the interval of 3 months, 6 months and yearly thereafter. An ultrasound examination for the upper tracts and a videocystometrogram (VCMG) was carried out at 3 months postsurgery and then yearly.

Results: The follow-up ranged from 3 to 133 months (mean 70.2 months). All implants were activated successfully with no intra- or immediate-postoperative complications. At activation all patients reported total urinary continence with seven out of nine implants (77\%) currently working well. Two patients reported significant recurrent incontinence at 3 month follow-up, one of whom underwent a removal of the entire implant at the end of 3 months and the other was continent after a pump and cuff revision. The implant removed at 3 months was due to erosion and infection while the second was removed at 24 months due to secondary implant infection. Three out of seven (43\%) successful implants required one revision each. One patient continues to report minimal leakage only during transfers with no leak demonstrated on postoperative VCMG. One patient with indwelling urethral catheter, two with suprapubic catheter and one voiding on urge have changed their bladder management to intermittent catheterisations postoperatively. All removals and revision procedures were carried out in the first 53 months of follow-up and four out of seven implants $(57 \%)$ required no revisions.

Conclusion: On a long term, AMS 800 is a viable option to treat USI in men with SCL. Mechanical revisions are frequent but effective. Strict patient selection, optimum preoperative bladder management and regular follow-up ensure low complication and high efficacy rates in the long term.

Spinal Cord (2006) 44, 297-300. doi:10.1038/sj.sc.3101843; published online 25 October 2005

Keywords: continence; male; AMS 800; spinal cord lesion; long term

*Correspondence: P Patki, Department of Neurourology, Spinal Injuries Unit, Royal National Orthopaedic Hospital, Stanmore, Middlesex HA7 4LP, UK

\section{Introduction}

International Continence Society defines urinary incontinence as complaint of any involuntary leakage of urine. ${ }^{1}$ Its prevalence rates range from 4.5 to $53 \%$ in female and 1.6 to $24 \%$ for male subjects. ${ }^{2}$ 
In spinal cord injury (SCI) patients urodynamic stress incontinence (USI) is associated with sphincter weakness secondary to neurological damage or sphincterotomy carried out in the past. It is complicated further by neurogenic detrusor over activity (NDO) seen in most suprasacral cord injuries. More than $80 \%$ of spinal injuries are seen in male subjects and approximately $67 \%$ of these are in individuals less than 30 years of age. $^{3}$ In this patient group incontinence is severely distressing problem resulting in low self-esteem, leading to lack of social interactions particularly sexual relations.

Varieties of methods have been tried in the past to achieve continence. Penile clamps and external continence devices are cumbersome and not preferred by younger generation aware of body image. Indwelling urethral catheters have high incidence of epididymitis and urethral strictures. ${ }^{4}$ Surgery on bladder neck and urinary diversion requires stoma formation and a collection device or bladder emptying with intermittent catheters. Puboprostatic sling repair has overall success rate of $83 \%$ at a mean follow-up of just over 1 year in SCI men with USI but requires intermittent catheterisations. ${ }^{5}$ The USI can also be treated with peri-urethral injections of bulking agents or artificial urinary sphincter (AUS). Recently, 36\% continence rates were quoted with polydimethylsiloxane, at a mean follow-up of 20 months, in incontinent male spinal injury patients. ${ }^{6}$

Scott $e t a l^{7}$ were first to report the use of silicone AUS for treatment of urinary incontinence in 1973. Generally complications like urethral atrophy, erosion and infection secondary to AUS implantation are reported to be more in patients with neurogenic bladder with USI. ${ }^{8}$ Over the past few years, developments were made in the design of the AUS, which has made it more reliable and easily implantable.

We report our long-term experience with American Medical System (AMS) 800 AUS used exclusively to treat USI in male patients with spinal cord lesion (SCL).

\section{Patients and methods}

A retrospective analysis identified nine men with SCL who underwent AMS 800 AUS implantation for neurogenic USI. Five had thoracic lesions (T11: $n=2$, T6: $n=2$, T7: $n=1)$, three lumbar (L1: $n=2, \mathrm{~L} 3: n=1)$ and one cervical (C7: $n=1)$. Apart from one patient with T6 complete SCL due to transverse myelitis, all other men had traumatic SCI (Table 1). The mean age was 38.2 years (range 27-47 years) and mean time since spinal lesion was 13.8 years (range 6-26 years). Seven patients were classified as complete lesions and two were incomplete.

All patients had significant and symptomatic USI demonstrated on preoperative video cystometrogram (VCMG). The mean bladder capacity on preoperative VCMG was $413 \mathrm{ml}$ (range $250-510 \mathrm{ml}$ ). Based on VCMG, NDO was noted in two cases with thoracic level injury and one with incomplete lumbar spinal injury. One of the thoracic SCI patients had augmenta-
Table 1 Patient demographics

\begin{tabular}{lcll}
\hline $\begin{array}{l}\text { Age } \\
\text { (years) }\end{array}$ & $\begin{array}{c}\text { Level of } \\
\text { lesion }\end{array}$ & $\begin{array}{l}\text { Complete/ } \\
\text { incomplete }\end{array}$ & Aetiology \\
\hline 39 & C7 & Complete & Trauma \\
47 & T6 & Complete & $\begin{array}{l}\text { Trauma } \\
\text { Transverse } \\
\text { Complete }\end{array}$ \\
35 & T6 & Complete & Trauma \\
29 & T7 & Complete & Trauma \\
45 & T11 & Complete & Trauma \\
37 & T11 & Incomplete & Trauma \\
42 & L1 & Complete & Trauma \\
43 & L1 & Incomplete & Trauma \\
27 & L3 & & \\
\hline
\end{tabular}

tion ileocystoplasty while the other underwent a sacral anterior root stimulator implant (SARSI) with posterior rhizotomy to control NDO. Regular oxybutynin was effective in controlling the NDO in lumbar SCI patient. Five patients had acontractile detrusor. Low compliance was an issue in one of the patients but the pressure changes were only seen at volumes in excess of $250 \mathrm{ml}$ on the VCMG.

Preoperatively, three patients managed their bladder with clean self-intermittent catheterisations (CSIC) and one voided on reflex and one on urge. Two patients had long-term suprapubic catheter (SPC) and one had indwelling urethral catheter (IDUC). One patient underwent a SARSI procedure with posterior rhizotomy. All patients were either using condom sheaths or pads to keep themselves dry. Two patients had previously failed surgery with endoscopic injection of polydimethylsiloxane and coaptite.

All the sphincters were implanted with the urethral cuff around the bulbar urethra via a perineal approach. One of the cuffs had to be revised and was repositioned around the bladder neck. A $61-70 \mathrm{~cm}$ water reservoir was used in all patients. At 6 weeks into the postoperative period, all the implants were successfully activated and baseline clinical assessment for continence was carried out at the same time. All patients were regularly followed up in outpatient clinics at the interval of 3 months, 6 months and yearly thereafter. Postoperatively an ultrasound examination for the upper tracts and VCMG was carried out at 3 months and then yearly. Routine blood investigations including renal function tests were carried out at 6 months interval initially and then carried out yearly. GFR measurement and isotope scans were requested when upper tract changes were noticed on ultrasound. All further surgical procedures and all complications were documented.

We defined cure as cessation of condom sheath or pad usage, along with confirmation of continence on VCMG results.

\section{Results}

All procedures were completed successfully with no intra-operative or immediate postoperative complica- 
Table 2 Complications and mechanical failures (5/9 patients)

\begin{tabular}{lcl}
\hline Complication & $\begin{array}{c}\text { Time of procedure } \\
\text { (months) }\end{array}$ & Procedure \\
\hline $\begin{array}{l}\text { Cuff erosion and } \\
\text { infection }\end{array}$ & 3 & Implant removal \\
$\begin{array}{l}\text { Cuff failure } \\
\begin{array}{l}\text { Secondary } \\
\text { infection of scrotal } \\
\text { pump }\end{array}\end{array}$ & 12 & $\begin{array}{l}\text { Revision of cuff } \\
\text { Implant removal }\end{array}$ \\
$\begin{array}{l}\text { Pump failure } \\
\text { Cuff erosion }\end{array}$ & 24 & $\begin{array}{l}\text { Revision of pump } \\
\text { Revision of cuff to } \\
\text { bladder neck }\end{array}$ \\
\hline
\end{tabular}

tions. All implants were activated at 6 weeks postoperatively without any complications. The pad test conducted on the day of the activation revealed $100 \%$ continence rates with no patients reporting leakage.

The follow-up ranged from 3 to 133 months (mean 70.2 months). At 3 months, two patients had recurrent incontinence seen on pad test, which was further confirmed on VCMG. In one of the incontinent patients the implant cuff eroded into the urethra and was secondarily infected. The implant was subsequently removed. In the second incontinent patient malfunctioning cuff tubing was subsequently revised with restoration of continence at the end of first year. At the end of 24 months, scrotal pump of another implant got secondarily infected by spread of infection from acute epididymoorchitis, resulting in removal of the second implant (Table 2). Seven out of nine implants $(77 \%)$ are currently functioning well with one patient still getting mild leak on transfers, which does not require a pad or a condom drain. No incontinence could be demonstrated on follow-up VCMG in this patient.

Three out of seven successful implants $(43 \%)$ required one revision each (Table 1). One patient required urethral cuff removal at the end of 53 months due to erosion. The cuff was subsequently replaced at the bladder neck and he is continent on further follow-up for 28 months. The two other patients had one successful mechanical revision each for cuff and pump dysfunction at the end of 12 and 36 months. Overall $57 \%$ of the successful implants have had no revisions and have the original implant at a mean follow-up of 105.2 months.

No upper tract change or deterioration in renal function was noted in any patient. Four out of seven patients with working implants recorded higher maximum detrusor pressures in follow-up VCMG. The bladder capacity did not show any significant changes. Two patients with SPC drainage, one with IDUC and one voiding on reflex changed their management to CSIC postoperatively.

\section{Discussion}

Over the years a variety of AMS artificial urinary sphincters have been used to treat neurogenic urinary incontinence. The success rate for previous models (AS 742 and AS 791/792) was 55 and $90 \%$, respectively. ${ }^{9}$ The overall success rate of models AS 791/792 in obtaining continence in SCI patients was $70 \%{ }^{10}$ There are some reports in literature evaluating efficacy of AS 800 model in treating neurogenic and non-neurogenic urinary incontinence. Complete postactivation continence rates of $83.5 \%$ have been reported with AS 800 in patients with total urinary incontinence. ${ }^{11}$ With the introduction of narrow backing occlusive cuff design the mechanical failure rates of AS 800 have dropped to $7.6 \%$ with $72 \%$ patients requiring no further surgical intervention at a mean follow-up of 68.8 months. ${ }^{12}$ Kryger et al $^{13}$ report excellent continence rates after a mean 15-year followup of AUSs used in neurogenic incontinence in paediatric population with revision rates of 0.03 revisions per patient-year.

In the present series, $77 \%$ patients were continent at a mean follow-up of 70.2 months. This compares favourably with the continence rates of $70-83.5 \%$ reported in the literature using AS 800 in neuropathic and non-neuropathic incontinence. ${ }^{10,11,14}$ In our experience, $5 / 9$ patients $(55 \%)$ required operative procedures for various complications. All five procedures were performed within the first 53 months of follow-up. Two of the five were explantations of entire sphincter secondary to infection and/or erosion. Two of the remaining three were revisions for mechanical failure, while one patient required surgical intervention for cuff erosion. This was corrected by placement of cuff at bladder neck that continues to work satisfactorily. These rates are quite similar to the revision and explantation rates quoted in series reporting functional outcome and durability of AMS 800 in patients with intrinsic sphincter deficiency. ${ }^{15}$ In our series $4 / 9$ patients $(45 \%)$ required no surgical revision after AMS 800 implantation for a mean follow-up of 105.2 months, which is comparable to a long-term follow-up of AMS 800 in paediatric population with neurogenic bladders. ${ }^{16}$

There are reports in the literature observing worsening detrusor function and upper tract dilatation postsphincter implantation for neuropathic incontinence. ${ }^{17,18}$ In our series no upper tract dilatation was seen on regular ultrasound scans for the entire duration of the follow-up. Changes seen in mean bladder capacity and compliance were not as significant as quoted in some of the literature. ${ }^{19}$ This may be due to the careful selection of patients with good preoperative bladder capacity and adequate preoperative treatment of NDO.

Even though the AUS is a satisfactory and a successful method of treatment for USI, high complication rates up to $45 \%$ are quoted of which $29 \%$ are sphincter related. ${ }^{20}$ Neurogenic incontinence patients have statistically higher rate of nonmechanical failure than non-neurogenic group leading to higher reoperation rates. ${ }^{21}$ In our series even though the number of patients is small, the follow-up is for a mean period of 70.2 months with the longest being 133 months. Our mechanical failures and revision rates are not so 
dissimilar to the published literature on AUS use in nonneurogenic incontinence.

Poor healing capacity, increased rates of recurrent UTI and skin condition may play a role in high rates of implant infection in patients with SCL. Therefore, patient selection in men with SCL is the key to good results and low complication rates. Manual dexterity, hand function and ability to operate pump in the scrotum when sitting on the wheel chair are some of the major patient selection criteria that require consideration. Long time spent sitting in the wheel chair should perhaps be taken into account when deciding the placement of urethral cuff to improve drainage and keep erosion rates to a minimum.

In view of high revision rates and not so uncommon complications with AUS, minimally invasive option like injections of bulking agent and more definitive treatment like puboprostatic sling procedure could be considered first line management in treating USI in SCL patients. However, till their longer term ( $>5$ years) results are available and expertise for male sling procedures is accesible in more centres, AUS could still be an attractive choice in a well informed and well selected patient.

\section{Conclusion}

On a long term, AMS 800 is a viable option to treat USI in men with SCL. Although revisions are common they are effective. Stricter inclusion criteria with wellinformed patient on optimum bladder treatment and long-term regular follow-up can ensure comparable cure and complication rates seen in non-neuropathic USI population. More long-term multi institutional studies with greater number of patients are required to define the exact role of AUS in the treatment of USI in men with SCL.

\section{Acknowledgements}

We thank Mr J Bycroft, Registrar in Urology, Institute of Urology and Nephrology London for his help in preparation of the presentation of this study (Abstract no. 454) at the ICS and IUGA 2004.

\section{References}

1 Abrams $\mathrm{P}$ et al. The standardisation of terminology of lower urinary tract function: report from the Standardisation Sub-committee of the International Continence Society. Neurourol Urodyn 2002; 21: 167-178.

2 Hampel C, Wienhold D, Benken N, Eggersmann C, Thuroff JW. Definition of overactive bladder and epidemiology of urinary incontinence. Urology 1997; 50: 4-14.
3 Stover SL, Fine PR. The epidemiology and economics of spinal cord injury. Paraplegia 1987; 25: 225-228.

4 Weld KJ, Dmochowski RR. Effect of bladder management on urological complications in spinal cord injured patients. J Urol 2000; 163: 768-772.

5 Daneshmand $\mathrm{S}$ et al. Puboprostatic sling repair for treatment of urethral incompetence in adult neurogenic incontinence. J Urol 2003; 169: 199-202.

6 Hamid R, Arya M, Khastgir J, Patel HR, Shah PJ. The treatment of male stress urinary incontinence with polydimethylsiloxane in compliant bladders following spinal cord injury. Spinal Cord 2003; 41: 286-289.

7 Scott FB, Bradley WE, Timm GW. Treatment of urinary incontinence by implantable prosthetic sphincter. Urology 1973; 1: 252-259.

8 Garcia MF, Gomez SF, Mundy A. Artificial urinary sphincter. Arch Esp Urol 2000; 53: 201-210.

9 Jakobsen H, Hald T. Management of neurogenic urinary incontinence with AMS artificial urinary sphincter. Scand J Urol Nephrol 1986; 20: 137-141.

10 Light JK, Scott FB. Use of the artificial urinary sphincter in spinal cord injury patients. J Urol 1983; 130: 1127-1129.

11 Goldwasser B, Furlow WL, Barrett DM. The model AS 800 artificial urinary sphincter: Mayo Clinic experience. J Urol 1987; 137: 668-671.

12 Elliott DS, Barrett DM. Mayo Clinic long-term analysis of the functional durability of the AMS 800 artificial urinary sphincter: a review of 323 cases. J Urol 1998; 159: 1206-1208.

13 Kryger JV et al. The outcome of artificial urinary sphincter placement after a mean 15 year follow up in a paediatric population. BJU Int 1999; 83: 1026-1031.

14 Malloy TR, Wein AJ, Carpiniello VL. Surgical success with AMS $800 \mathrm{GU}$ sphincter for male incontinence. Urology 1989; 33: 274-276.

15 ter Meulen PH, Zambon V, Kessels AG, van Kerrebroeck PE. Quality of life, functional outcome and durability of the AMS 800 artificial urinary sphincter in patients with intrinsic sphincter deficiency. Urol Int 2003; 71: 55-60.

16 Simeoni J et al. Artificial urinary sphincter implantation for neurogenic bladder: a multi-institutional study in 107 children. Br J Urol 1996; 78: 287-293.

17 Light JK, Pietro T. Alteration in detrusor behavior and the effect on renal function following insertion of the artificial urinary sphincter. J Urol 1986; 136: 632-635.

18 Murray KH, Nurse DE, Mundy AR. Detrusor behaviour following implantation of the Brantley Scott artificial urinary sphincter for neuropathic incontinence. $\mathrm{Br} \mathrm{J} \mathrm{Urol}$ 1988; 61: 122-128.

19 Churchill BM, Gilmour RF, Khoury AE, McLorie GA. Biological response of bladders rendered continent by insertion of artificial sphincter. J Urol 1987; 138: 1116-1119.

20 Nurse DE, Mundy AR. One hundred artificial sphincters. Br J Urol 1988; 61: 318-325.

21 Murphy $\mathrm{S}$ et al. A comparison of the functional durability of the AMS 800 artificial urinary sphincter between cases with and without an underlying neurogenic aetiology. Ir J Med Sci 2003; 172: 136-138. 